\title{
Festival de Parintins - a epopeia cabocla e a semiose linguística e cultural
}

\author{
Festival de Parintins - la epopeia cabocla y la semiose linguistica y \\ cultural \\ Parintins Festival - the cabocla epic and the linguistic and cultural \\ semiose
}

Djane da Silva Sena ${ }^{1}$

Priscila de Oliveira Pinto Maisel $^{2}$

\begin{abstract}
Resumo
Estamos acostumados a valorizar a arte contida em telas e esculturas tudo o que mais aprendemos dentro dos padrões tradicionais. A obra só pode ser vista a partir de sua inserção como agente da história, portanto, uma história especial que, por sua vez, opera num campo específico e tem metodologias próprias, mas que, ao final, enquadra-se na história geral da cultura, explicando como será a cultura elaborada e construída pela arte. No contexto da cultura artística contemporânea, temos o Festival de Parintins. No meio da imensidão da floresta e dos rios da Amazônia, acontece um espetáculo a céu aberto, onde os Bois Garantido e Caprichoso enfrentam-se para o deleite de cerca de 80 mil turistas. Tal como em um teatro, assistimos a uma epopeia cabocla numa grande semiose linguística e cultural, mítica e histórica. Personagens e elementos imaginários como fontes de ligação e origem através do mito que nada mais é do que a encenação poética da linguagem. En esta investigación, buscamos compreender a importância da cultura do boi-bumbá para a região amazônica e como esta cultura se (re)constrói simbolicamente. Como metodologia, utilizamos a pesquisa qualitativa com abordagem descritiva. Como resultados, identificam-se simbolicamente sujeitos e histórias comuns a outras que se revelam memórias de temas correlatos à cultura indígena, cabocla e religiosidade, narrativas simbólicas, transmitidas de geração a geração.
\end{abstract}

Palavras-chave: boi bumbá, cultura amazônica, cultura indígena, semiótica, arte.

\section{Resumen}

Estamos acostumbrados a valorar el arte contenida en pantallas, esculturas y todo lo que aprendemos dentro de los modelos tradicionales. La obra sólo puede ser vista a partir de su inserción como agente de la historia, por lo tanto, una historia especial, que a su vez opera en un campo específico y tiene metodologías propias, pero que al final, se enmarca en la historia general de la cultura, explicando como será la cultura elaborada y construida por el arte. En el contexto de la cultura e del arte contemporáneo, tenemos el Festival de Parintins. En medio de la inmensidad del bosque y de los ríos de la Amazonia, ocurre un espectáculo a cielo abierto, donde los Bois, Garantido y Caprichoso, se enfrentan para el deleite de unos 80 mil turistas. Al igual que en un teatro, asistimos a una epopeya cabocla en una gran semiosis lingüística e cultural, mítica e histórica. Personajes y elementos imaginarios como fuentes de conexión y origen a través del mito que nada más es que la escenificación poética del lenguaje. En esta investigación, buscamos comprender la importancia de la cultura del boi bumbá para la región amazónica y cómo esta cultura se (re) construye simbólicamente. Como metodología, utilizamos la

\footnotetext{
${ }^{1}$ Graduada em Artes Visuais. Universidade Federal do Amazonas; Manaus; Amazonas; Brasil;

email:lisblanc_am@hotmail.com.
}

\footnotetext{
${ }^{2}$ Mestre em Sociedade e Cultura. Universidade Federal do Amazonas. Manaus. Amazonas; Brasil. E-mail: priscilapinto@gmail.com
} 
investigación cualitativa con enfoque descriptivo. Como resultados, se identifican simbólicamente sujetos e historias comunes a otras que se revelan memorias de temas relacionados con la cultura indígena, cabocla y religiosidad, narrativas simbólicas, transmitidas de generación a generación.

Palabras clave: boi bumbá, cultura amazônica, cultura indígena, semiótica, arte.

\begin{abstract}
We are accustomed to value the art contained in canvases, sculptures and everything we learn in tradicional models. The work can only be seen from its insertion as an agent of history, therefore, a special history, which in turn operates in a specific field and has its own methodologies, but which, in the end, fits into the general history of culture, explaining as will be the culture elaborated and constructed by the art. In the context of contemporary art and culture, we have the Parintins Festival. In the middle of the vastness of the forest and rivers of the Amazon, there is an open-air show where the Bois, Garantido and Caprichoso, face each other to the delight of about 80 thousand tourists. As in a theater, we witness a cabocla epic in a great linguistic and cultural semiotic, mythical and historical. Characters and imaginary elements as sources of connection and origin through the myth that is nothing more than the poetic staging of language. In this research, we seek to understand the importance of the Bumbá ox culture for the Amazon region and how this culture is (re) constructed symbolically. As a methodology, we used qualitative research with a descriptive approach. As results, symbolically identify subjects and stories common to others that reveal memories of issues related to indigenous culture, cabocla and religiosity, symbolic narratives, transmitted from generation to generation.
\end{abstract}

Key words: boi bumbá, Amazonian culture, indigenous culture, semiotics, art.

\title{
1. Introdução
}

A arte não é apenas uma forma de encantamento, mas também fonte de conhecimento. Para Zamboni (2006, p.08), para se fazer arte de forma consciente é necessário ou pelo menos desejável, que se conheça o percurso realizado por outros artistas e outras escolas em épocas diversas. Contudo, muitos estão acostumados a supervalorizar a arte contida em telas, esculturas e tudo aquilo que se aprende dentro da sala de aula. $\mathrm{O}$ senso comum é que a arte deriva do emocional.

Para Giulio Carlo Argan (1992, p.19), a obra é vista como obra de arte quando tem importância na história da arte e contribui na formação e desenvolvimento de uma cultura artística, concluindo assim, que "o juízo que reconhece a qualidade artística de uma obra, dela reconhece ao mesmo tempo a historicidade". Para o teórico, a obra só pode ser vista a partir de sua inserção na história, identificando-a "não como um reflexo, mas como agente" nesse processo; não só ela é fruto de um contexto sócio histórico, como esse contexto é fruto da própria obra. Ambos estão a fazer-se, ao mesmo tempo, o tempo todo, não sendo possível compreender a arte do passado sem compreender a arte da nossa época.

No contexto da cultura amazônica, situado diante de um cenário magnífico, temos o Festival Folclórico de Parintins. Um espetáculo de proporções monumentais, a céu aberto, no 
meio da floresta amazônica, na Ilha Tupinambarana ${ }^{3}$, onde os Bois Garantido, o boi do coração na testa, representado pela cor vermelha, e o Boi Caprichoso, o touro negro com a estrela na testa, representado pela cor azul, se enfrentam, para o deleite de cerca de 80 mil turistas de todas as partes do mundo, segundo dados da Amazonastur, órgão do Governo do Estado do Amazonas, responsável pela organização do evento.

Nesta pesquisa intitulada "Festival Folclórico de Parintins - A epopeia cabocla e a semiose linguística e cultural" abordaremos a conversão semiótica dentro do Festival de Parintins, através da identificação da semiosfera ${ }^{4}$ que envolve a construção do espetáculo. Esta pesquisa é um desdobramento do projeto de iniciação científica Referenciais indígenas no contexto do boi-bumbá de Parintins, registrado sob n PIB-H 0023/2017, através do qual mapeamos as lendas amazônicas e rituais indígenas apresentados no Festival de Parintins no período de 2013 a 2015. Esse período foi estendido para os anos de 2016 a 2018, no Trabalho Final de Curso da autora.

Em Parintins, além de se desenvolver processos altamente criativos, construiu-se um sistema cultural singular. O mais importante conceito formulado, além do imaginário como norteador da cultura amazônica, é o da conversão semiótica, isto é, o processo de mudança na qualidade do signo e ou símbolos na narrativa de uma história, mito, conto ou similares através da linguagem. Esta, por sua vez, quer seja escrita, falada ou interpretada. Podemos compreender como a cultura produz ininterruptamente cultura, a partir da compreensão da cultura como um grande espaço semiótico e de como esse sistema é produtor de outros textos, gerando assim, uma continuidade semiótica.

Ao tomar a conversão semiótica dentro do Festival de Parintins como cerne do debate, esta pesquisa busca responder ao seguinte problema: Como se dá a conversão semiótica dentro do Festival Folclórico? Quais os subsistemas culturais que formam a linguagem plural presente no Festival e de que forma elas colaboraram para o Festival como é

\footnotetext{
${ }^{3}$ Arquipélago situado no Amazonas, cuja área é dividida, de sudoeste a nordeste, entre os municípios de Nova Olinda, Itacoatiara, Urucurituba, Boa Vista do Ramos, Barreirinha e Parintins. Sendo que Parintins é a mais populosa. O topônimo "Tupinambarana" é uma referência aos antigos habitantes do arquipélago, os índios tupinambaranas.

${ }^{4}$ distintos sistemas, e que "la separación de éstos [sistemas] está condicionada únicamente por una necesidad heurística. Tomado por separado, ninguno de ellos tiene, en realidad, capacidad de trabajar. Sólo funcionan estando sumergidos en um continuum semiótico, completamente ocupado por formaciones semióticas de diversos tipos y que se hallan en diversos niveles de organización" (LOTMAN, 1996, p. 22). Irene Machado (2007) define a semiosfera como um espaço-tempo onde formações semióticas de diversos tipos que se encontram em diversos níveis de organização podem transitar e interagir de forma dinâmica.
} 
hoje? Como se se dão as relações entre os sistemas culturais existentes no Festival de Parintins?

Assim, entendemos a cultura do boi-bumbá tecida na relação entre homem e natureza e reinventada na arte e no folclore como uma cultura viva, em evolução, integrada e formadora da identidade amazônica. Cultura esta que no sentido ético e estético que Loureiro (2015) chamou de paidea ${ }^{5}$, de Bildung $^{6}$ amazônica, constituída por indivíduos formados segundo um modo de relação profunda com a natureza e dos homens entre si.

\title{
1. Justificativa e fundamentos
}

Ao considerarmos o Festival Folclórico de Parintins como um dos maiores festejos populares do Brasil e a maior festa folclórica da região Norte, percebemos a importância de estudos acerca deste festival para auxiliar na compreensão da identidade e desenvolvimento cultural não apenas da população amazônica, mas de todos os envolvidos no desenrolar do espetáculo. A partir dessa perspectiva, podemos dizer que o Festival Folclórico de Parintins carrega a carga de patrimônio cultural do povo amazônico, não sendo hoje apenas um evento isolado, mas como uma interação entre sujeitos, lugar, história, memórias e ancestralidade, uma interlocução com o passado e a formação de simbologias e sentidos nesse vasto território cultural que é o festival.

O interesse pelo tema surgiu devido às memórias criadas na infância, narrativas de caráter individual e coletivo. E de objeto, já que também a mesma faz parte do processo de criação de um boi-bumbá em Manaus. A soma destas experiências deu origem ao propósito de construir, organizar e socializar memórias e entender como isso contribui para que essa cultura permaneça viva. Nesse sentido, Zamboni (2006) nos diz que:

\begin{abstract}
A maneira de ver e perceber o objeto está relacionada ao paradigma que o indivíduo se propõe a vivenciar. O processo de percepção e comunicação do cientista é diferente do artista; a diferença não está obviamente, no fato de ambos possuírem individualidades características de cada ser humano, mas sim nos diferentes paradigmas que instruem o olhar do artista e do cientista. (ZAMBONI, 2006, p. 64).
\end{abstract}

Para Amaral (2012) a arte dos artistas de países da América Latina sempre foi

\footnotetext{
${ }^{5}$ Paideia ( $\left.\pi \alpha \downarrow \delta \varepsilon i ́ \alpha\right)$ é um termo do grego antigo, empregado para sintetizar a noção de educação na sociedade grega clássica. Inicialmente, a palavra (derivada de paidos (pedós) - criança) significava simplesmente "criação dos meninos", ou seja, referia-se à educação familiar, os bons modos e princípios morais.

${ }^{6}$ É a tradução alemã para o termo grego Paideia, o qual traduzimos - sem que tenhamos algo com sentido equivalente - por "formação" ou por "cultura", mas carrega consigo o sentido de uma formação harmônica do todo da personalidade, em suas variadas possibilidades, de modo a viabilizar a realização da obra de arte
} 
considerada pelos europeus como uma arte de segunda classe, uma arte periférica que segue de longe ou de mais perto as tendências artísticas internacionais. Parece evidente que quando um país se apresenta como uma cultura forte, como é o caso do México, com um presente fruto de uma trajetória cultural, de um passado cultuado e preservado como uma memória que deve orgulhar um cidadão, este dado já é, de per se, um motivo de respeitabilidade, independente do fato de que o México se constituiu, na década de 30, com o muralismo a mais forte influência estrangeira na arte norte-americana. É por isso, que esta cultura tão mista vivenciada no Festival de Parintins, demanda uma urgente e contínua investigação em todas as áreas do conhecimento presentes na festa, pois investigação em arte também é criação.

Da Amazônia Quaternária7, do Boi Caprichoso, às Nações Extintas ${ }^{8}$, do Boi Garantido, a cultura do boi-bumbá canta e encena desde o período pré-histórico à colonização do Brasil, numa aula de História ao vivo, fornecendo informações do passado de todo território amazônico, a partir de uma vasta pesquisa documental interpretada artisticamente.

Para fundamentar teoricamente esta pesquisa, tomamos por base conceitos ligados à Cultura, Cultura Amazônica, Cultura Popular, Cultura Indígena, Semiótica e História da Arte. Para tanto, importantes são as referências de Loureiro (2015), Braga (2002), Lotman (1996, 2000), Machado (2003), entre outros teóricos e pesquisadores.

\section{Discussões e Resultados}

\subsection{Memórias de um festival: fragmentos da história}

No final do século XIX, começava a história dos bois de Parintins, Garantido e Caprichoso. Tenório (2016, p. 66) nos informa que, nesta época, estabeleceu-se na cidade, o sr. Alexandre Silva, que comprou algumas terras de várzea na área do lago do Valente, há algumas horas acima de Parintins, onde passou a trabalhar com agricultura. Casou-se com uma mulher de ascendência negra e teve uma filha, a quem chamou de Alexandrina Silva, em sua própria homenagem. Alexandrina, mais conhecida por Xanda, seria a mãe de Lindolfo Marinho da Silva, que entraria para a história como Lindolfo Monteverde, o fundador do Boi bumbá Garantido. Na mesma época, oriundo de Crato-CE, chegava a Parintins, o nordestino

\footnotetext{
${ }^{7}$ Toada do Boi Caprichoso no ano de 1998, composição de Ronaldo Barbosa.
}

\footnotetext{
${ }^{8}$ Toada do Boi Garantido no ano de 1996, composição de Sidney Rezende e João Melo.
} 
Roque Cid. Pedreiro com conhecimento autodidata em edificações. Pai de Nascimento Cid, Raimundo Cid (Mundico), Pedro Cid e Arthur Cid. Os irmãos Cid, com exceção de Mundico, seriam os fundadores do Boi Bumbá Caprichoso.

O boi-bumbá Garantido nasceu em 12 de junho de 1913, véspera de Santo Antônio, de uma promessa de Lindolfo Monteverde a São João Batista, quando este encontrava-se deveras enfermo: Caso vencesse a enfermidade, colocaria o boizinho todos os anos para brincar nos festejos de São João. O Boi Garantido é conhecido como "O boi do povão", possui um coração vermelho na testa (figura 01) e defende as cores vermelha e branca. Foi 31 vezes campeão do Festival, e sagrou-se campeão no ano do centenário dos bumbás, em 2013.

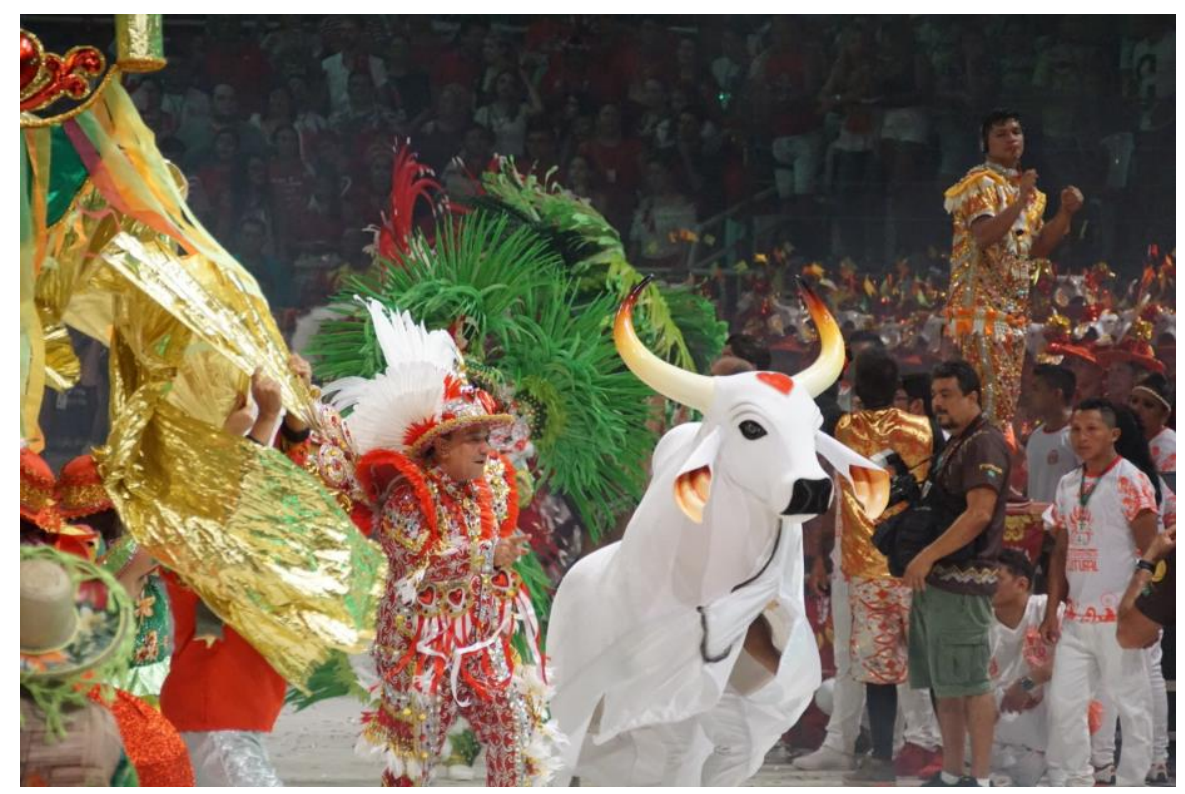

Figura 1 - Associação Folclórica Boi Bumbá Garantido, 2018

Fonte: Foto de Xavier Pernée, 2018.

Segundo a folclorista Odinéia Andrade apud Valentim (1999. p. 132), o Boi Caprichoso surgiu em 20 de outubro de 1913, também de uma promessa feita, desta vez, pelos irmãos Cid: se tivessem sucesso na nova terra (Parintins), colocariam um boi para dançar nas festas de São João. O Boi Caprichoso é conhecido como diamante negro, (figura 02) em razão deste ser todo na cor preta - ou o Boi de Parintins e possui na testa uma estrela, mas as cores que predominam são o azul e o branco. Possui 23 títulos e sagrou-se campeão no ano do jubileu de ouro do festival em 2015. 


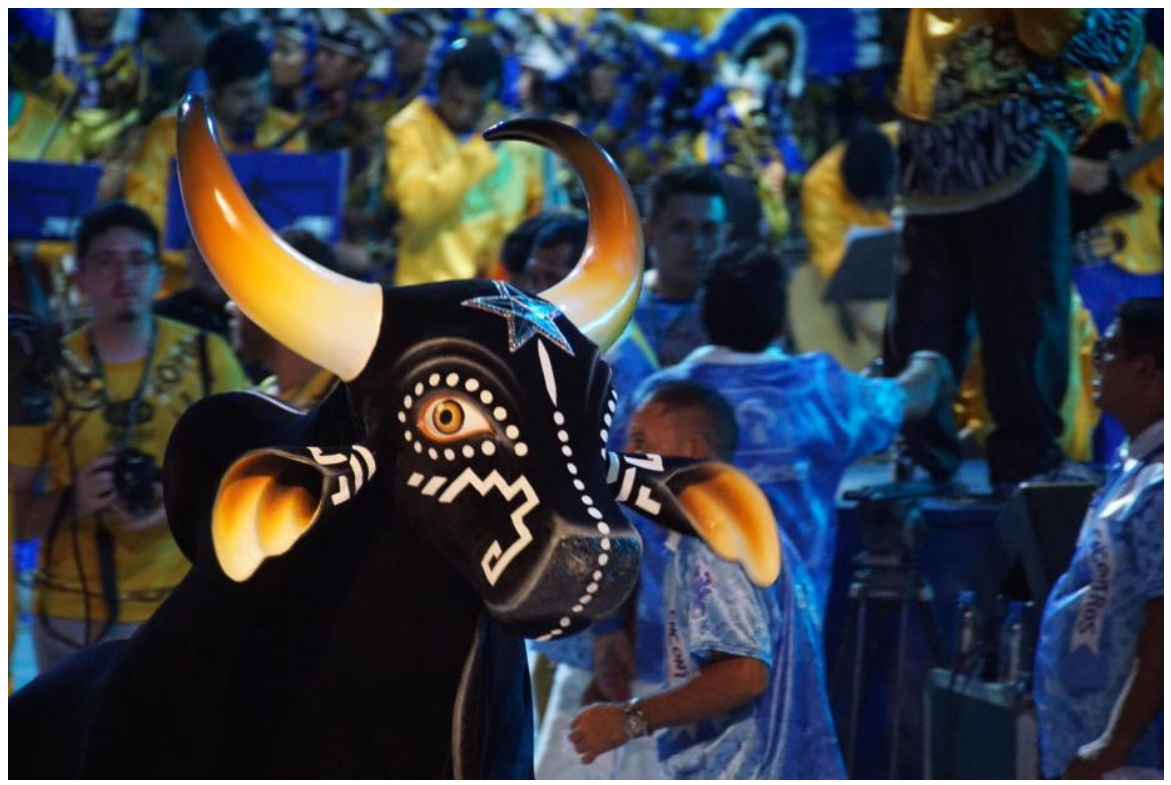

Figura 2 - Associação Folclórica Boi Bumbá Caprichoso, 2018

Fonte: Foto: Xavier Pernée. 2018

Para Furlanetto (2011, p.03), o espetáculo do Festival de Parintins é uma espécie de ópera popular, uma peça teatral a céu aberto, resultante da união de elementos das culturas europeia, africana e indígena, no qual o boi é a principal figura de representação. Presente em diversas regiões do pais, o eixo propulsor do folguedo se desenvolve, basicamente, em torno de um rico fazendeiro (elemento branco) cujo boi de estimação é roubado por Pai Francisco, negro escravo da fazenda que mata o animal do seu senhor para satisfazer o desejo de sua esposa grávida, Mãe Catirina, que quer comer a língua do boi. Pajés e curandeiros (elemento ameríndio) são convocados para reanimar o animal e, quando o boi ressuscita urrando, todos os brincantes cantam e dançam em redor do boi, em uma enorme festa para comemorar o milagre.

Os referenciais utilizados no festival, sejam indígenas ou caboclos, ligam-se à cultura e tradição popular, passada de geração em geração. Com o tempo e suas transformações, contribuíram para a construção de uma cultura contemporânea, que precisa ser entendida e devidamente estudada. De acordo com Assayag (1997, p.64), a mudança do bumba-meu-boi em boi bumbá na região amazônica deu-se justamente aos referenciais indígenas, enquanto Andrade (2002) nos ensina o boi-bumbá amazônico valoriza a cultura indígena - mesmo que de forma estilizada.

O festival folclórico foi criado em 1965, liderado por um grupo de jovens ligado à igreja a Juventude Alegre Católica (JAC), segundo Silva (2007, p. 26). Apesar do 
cristianismo e a cultura do boi-bumbá serem secularmente antagônicos, a maior parte da rapaziada da JAC era vinculada ao Boi Garantido e a finalidade do festival era contribuir para a construção da catedral de Nossa Senhora do Carmo. Com o festival, os bois passaram a se apresentar em um tablado, sendo avaliados em cinco quesitos: marcação, organização, vestuário, ritmo, animação e opinião pública. Desta forma, o julgamento implementava naquele momento o que viria a ser a competição, cujo resultado almejado passou a ser o título de campeão e o troféu.

Em 1976, o artista Jair Mendes inseriu as artes plásticas no universo folclórico do Boi Garantido, de acordo com Tenório (2016, p. 192). Sendo, até hoje, o que mais desperta o interesse da população, principalmente as gigantescas alegorias. Outras novidades foram sendo introduzidas a cada ano, e isso permitiu que os bois fizessem experiências a cada edição para chamar a atenção do público. Em 1978, o poeta Tonzinho Saunier inseriu os contos e lendas e Jair Mendes modificou a forma de fazer a estrutura do boi, antes feito com paus de igapós e talas de palmeiras, passaria a ser feito de fibras e esponjas. Em 1979, o artista Vandir Santos inventou e inseriu as alegorias em módulos. Foi a partir da década de 90, que surgiram as famosas alegorias articuladas.

E, assim, ano após ano, os bois foram se reinventando e se recriando para a cada ano, apresentar um espetáculo diferente e inventivo. Artistas de alegorias são mestres na arte de criar alegorias de tirar o fôlego literalmente de suas respectivas torcidas. São três dias que Parintins vive sob os holofotes da mídia e de uma plateia externa ávida por saber o que os bois reservam para cada noite. Turistas de todas as partes do mundo e cobertura de imprensa do país e do exterior, mostram o crescente investimento financeiro para a organização do festival e para a produção artística dos bumbás, bem como na qualidade do que se exibe. Isso mostra que o espetáculo é, de fato, grandioso, constituído por enormes alegorias, luxuosas fantasias e efeitos de luz e de som cada vez mais sofisticados. A magnitude do espetáculo, aliado ao lugar onde se realiza, são elementos relevantes nas manifestações de estranheza e espanto presentes em avaliações de parte da mídia sobre Parintins.

O visitante chega a estranhar o fato de ser possível a realização de evento de tamanha magnitude em plena floresta amazônica. Cada bumbá tem 02 horas e meia para se apresentar em cada uma das três noites. E, em cada apresentação, narra uma história diferente. Na arena do Bumbódromo existe respeito. Enquanto um boi se apresenta, a galera adversária observa em silêncio, cada ponto pode fazer a diferença na apuração. 
Localmente, disputa-se a vitória entre dois bois, com implicações para a vida cotidiana, pois, em Parintins não se considera o vice-campeonato. Para o turista, trata-se de um espetáculo grandioso no qual a vitória de um ou de outro não assume maior consequência; seu interesse está, sobretudo, no espetáculo em si, no que este representa como novidade, no qual são exibidas manifestações culturais de um mundo ligado às narrativas amazônicas.

\subsection{Semiótica da cultura e a Amazônia como um grande signo}

Nosso ponto de partida para esta pesquisa é a semiótica da cultura, pois no festival dos bois de Parintins, tal como em um teatro, assistimos a uma epopeia cabocla no que chamaremos de espaço semiótico com personagens e elementos imaginários como sistemas de signos. O universo amazônico explorado pelos Bois Garantido e Caprichoso relembra o que Loureiro (2015) identificou como um grande signo modulado pelo tempo.

Sobre a semiótica da cultura, Mesquita (2016, p.71) nos faz saber que ela surgiu a partir dos estudos nos encontros anuais que ocorriam durante os seminários de verão da Escola de Tartu-Moscou (ETM), nos anos 1960, na Universidade de Tartu, Estônia. Esses estudos buscavam compreender o papel da linguagem na cultura. Yuri Lótman foi o responsável pelos principais trabalhos norteadores desta corrente semiótica e definiu a semiótica da cultura como uma disciplina que investiga as relações entre os sistemas de signos diversamente estruturados. Nesses termos, Lótman (1996) afirma que:

La conformacion de la semiótica de la cultura - disciplina que examina la interaccion de sistemas semióticos diversamente estructurados, la no uniformidade interna del espacio semiótico, la necesidad del poliglotismo cultural y semiótico cambió em considerable medida las ideas semióticas tradicionales.

Nesta pesquisa, analisamos a cultura amazônica sob o ângulo dominante de uma poética advinda do imaginário cultural nela inserida ou proveniente. Assim, entendemos o Festival de Parintins como linguagem que dá origem a sistemas semióticos diversos, e estes, como um problema semiótico. Conforme identifica Mesquita (2016, p. 72) em seus estudos, a linguagem é qualquer sistema de signos que sirva a comunicação e a produção de cultura.

Ainda segundo Mesquita (2016, p.72) só podemos compreender a dinâmica da cultura a partir dos textos culturais, conceito esse imprescindível para os estudos semióticos da cultura, pois trata a cultura a partir de sua semiose, de seus processos semióticos e do funcionamento dos textos culturais na formação do tecido da cultura em estudo. A cultura é, dessa forma, tratada como um grande texto, e a comunicação como processo de semiose, ou ação do signo. Geradora de estruturalidade, e com isso cria em torno do homem uma esfera 
social que, como a biosfera, torna a vida possível, certamente não a orgânica, mas a social. Nesse caso, entende-se que, para exercer seu papel, "la cultura debe tener dentro de sí um “dispositivo estandarizante” estrutural. Esa función suya es desempeñada exactamente por el lenguaje natural" (Lótman, 2000. p.171).

Américo (2012, p.116) nos ensina que a própria cultura pode ser analisada como um texto, ou mais precisamente, um texto composto por outros textos, menores:

A cultura como um todo pode ser analisada como um texto. Entretanto, é muito importante destacar que é um texto de composição complexa que se divide em uma hierarquia de "textos dentro de textos" e que forma entrelaçamentos complexos de textos. Já que a própria palavra "texto" inclui a etimologia de entrelaçamento, podemos dizer que através dessa interpretação devolvemos ao conceito de "texto" o seu significado autêntico. (Lótman apud Américo, p.116)

Bakhtin apud Américo (2012, p.117) também utiliza o termo "texto" não apenas no sentido estritamente linguístico, mas também referente à cultura:

Se tomarmos o texto no sentido amplo de um conjunto coerente de signos, então também as ciências da arte (a musicologia, a teoria e a história das artes plásticas) se relacionam com textos (produtos da arte). Pensamentos sobre pensamentos, emoção sobre emoção, palavras sobre palavras, textos sobre textos.

No universo teórico de Lótman, o paralelo entre o texto e a cultura é crucial. É aqui que chegamos ao conceito de semiosfera, sugerido por Lótman apud Mesquita (2016, p.77). Só a partir da compreensão da cultura como um grande espaço semiótico, de como esse sistema é produtor de outros textos, gerando assim, uma continuidade semiótica, de modo que a cultura produz ininterruptamente cultura.

\subsection{Semiosfera - Delimitando o campo semiótico a ser estudado}

Ao definir a semiosfera como um "espaço semiótico" abstrato, Lótman dá a entender que são as trocas efetivadas entre diferentes sistemas modelizantes que delimitam e qualificam a semiosfera como espaço de relações. Sendo que ela possui vários traços distintos. No que diz respeito ao caráter delimitado, encontramos o conceito de fronteira. A fronteira para Lotman, é uma parte indispensável da semiosfera. Desse modo, o conceito de semiosfera apresenta os mecanismos necessários para a compreensão do espaço a ser estudado e as diferentes linguagens que transitam no espaço da semiosfera e o modo como ela é construída. 
Os referenciais utilizados no boi bumbá fizeram e, em alguns casos, ainda fazem parte da tradição de um povo, porém, contribuíram para a construção de uma cultura contemporânea. Assim, a representação da semiosfera (figura 03) inicialmente identificada no Festival de Parintins, ficou composta por 03 núcleos, cada uma com seu subsistema:

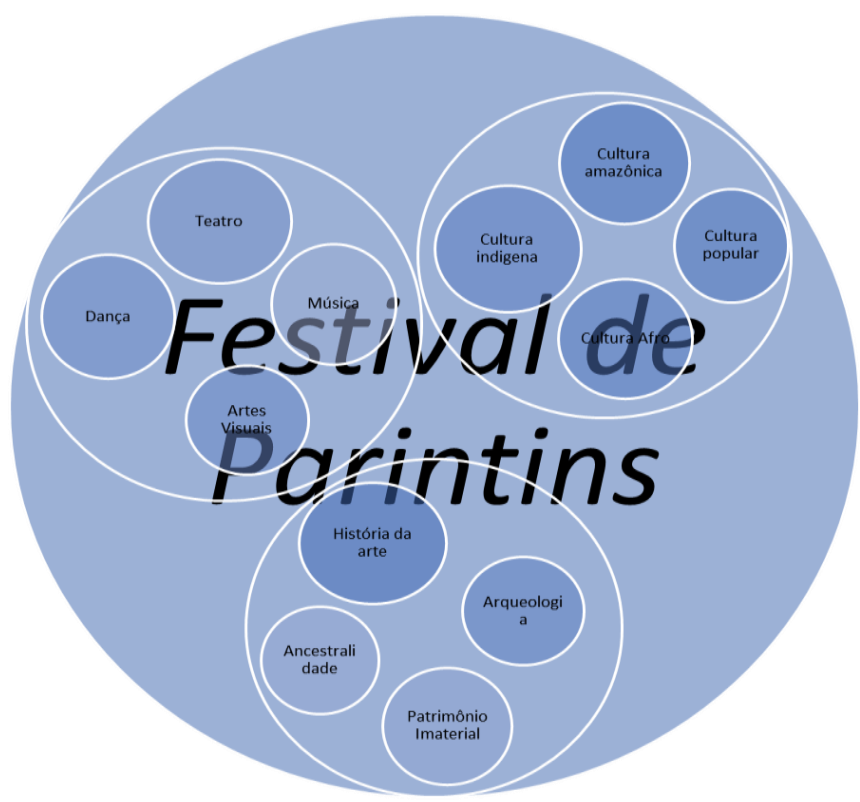

Figura 3 - Semiosfera do Festival de Parintins

Fonte: Criação da autora Djane Sena, 2018.

- Cultura: (cultura amazônica, cultura popular, cultura indígena e cultura afro)

- História: (patrimônio imaterial, arqueologia, história da arte e religião)

- Linguagens: (artes visuais, teatro, música e dança)

\subsection{Cultura, História e Linguagens como espaço semiótico a ser estudado}

\subsubsection{Cultura}

Compreender cultura determina alguns métodos de pesquisa. Pois ela nos permite examinar tanto etapas isoladas da cultura como todo o conjunto de fatos histórico-culturais na qualidade de uma espécie de texto aberto, aplicando em seu estudo, os métodos gerais da Semiótica. Lótman (2000, p.32) definiu cultura como "O conjunto de informações não hereditárias que as diversas coletividades da sociedade humana acumulam, conservam e transmitem". A partir de uma vasta pesquisa documental interpretada artisticamente, o boibumbá canta e encena a cultura popular, fornecendo informações do passado de todo território 
amazônico. Tais pesquisas podem ser consideradas, também, como o legado de povos que já não existem mais e, portanto, constituem-se como herança cultural.

Em essência, cultura é todo conhecimento que uma sociedade tem de si mesma, sobre outras sociedades, sobre o meio material em que vive e sobre sua própria existência. No início da década de 1980, nas convenções internacionais promovidas pela Organização das Nações Unidas para a Educação, Ciência e Cultura - Unesco, convencionou-se que "cultura" agrega também as maneiras de o ser humano existir, pensar e se expressar e as manifestações simbólicas dos seus saberes, práticas artísticas e cerimoniais, sistemas de valores e tradições. Esta noção de cultura adquiriu maior magnitude em 1985, por ocasião da "Declaração do México".

\subsubsection{Cultura Amazônica}

Ao analisar de forma mais profunda a cultura amazônica, percebemos um universo repleto de seres, signos, fatos, atitudes que indicam diversas possibilidades de análise e interpretação. Na perspectiva de estudo de Loureiro (2015), a cultura amazônica é resultante da miscigenação racial de integração cultural, onde a experiência da vida dos habitantes foi gerando, por sincretismo de elementos indígenas e europeus, uma cultura em que o devaneio do imaginário da sociedade ganhou especial importância.

Um devaneio que atua como ligação entre o real e o imaginário. Este último, atuando como o poetizante estetizador que é governado por um sistema de funções culturais. Um conjunto de relações culturais com o mundo, reguladas pelo poético que emana da liberdade do imaginário amazônico. Uma poética que se revela não somente nas criações dos diversos campos da arte, mas que também estabelece a forma de uma ética das relações dos homens entre si e com a natureza. Uma poética em ação que se instaura no cerne de uma cultura governada pela função estética do imaginário.

Podemos considerar que "o mito, como parte de nossa cultura, é vivo." (SILVA, s/d) e que, simultaneamente, é produto e instrumento de conhecimento e reflexão sobre o mundo, a sociedade e a história. Para Eliade (2010, p.11) é difícil achar uma definição de mito que seja aceita universalmente. Por outro lado, será realmente possível encontrar uma única definição capaz de cobrir todos os tipos e todas as funções dos mitos, em todas as sociedades arcaicas e tradicionais? O mito é uma realidade cultural extremamente complexa, que pode ser abordada e interpretada através de perspectivas múltiplas e complementares. 
Assim, o mito seria a história sagrada, um acontecimento ocorrido no tempo primordial, o tempo fabulosos do princípio. Graças as façanhas dos entes sobrenaturais, o mito seria uma realidade que passou a existir, o cosmo, ou ainda apenas um fragmento. Através dessas narrativas, as gerações mais jovens puderam compreender o tempo primordial e trazer para si como realidades, fazendo viver, na imaginação, os acontecimentos que lhe foram narrados. Isso contribui para a formação da identidade do homem como e onde ele vive, claro que isso só é possível com a aceitação e identificação desse homem com todos esses valores transmitidos e com o lugar onde vive.

No caso peculiar da Amazônia, muitos mitos indígenas foram se transformando em lendas ao longo dos anos, ou seja, as relações entre mitologia indígena e a lenda cabocla são muito próximas Se for comparado o conceito de lenda com o de mito, os dois se confundem, portanto, tem uma relação porque a lenda retrata o mito. As histórias da região amazônica, quanto mais conhecidas e exploradas, surpreendem com aspectos característicos, oferecendo uma visão de mundo mais ampla, embora numa cultura heterogênea e complexa como a da Amazônia.

\subsubsection{Cultura popular}

Para Braga (2007, p. 56), a noção de cultura popular ou "culturas do povo", surge como elemento diacrítico voltado para marcar diferenças, pressupondo sempre um contexto que constitui objeto de descrição e inventário por parte do antropólogo, cuja ênfase teórica recai sobre identidades contrastivas, entre letrados e iletrados ou, quem sabe, quando se trata de inquirir sobre a imaginação popular materializada em práticas ditas populares. Para o referido antropólogo, é necessário ressaltar a importância de uma cultura popular amazônica, ou melhor, a pertinência de se explorar referenciais teóricos e empíricos que nos permitam tratar do assunto com o intuito de fixar traços culturalmente relevantes.

\subsubsection{Cultura indígena}

Em 2010, o Brasil era composto de 190.755 .799 milhões de pessoas, e a população indígena no território nacional, composta de 817.963 mil pessoas, dos quais 502.783 viviam na zona rural e 315.180 habitavam as zonas urbanas brasileiras. São os dados do Censo Demográfico de 2010 do IBGE - Instituto Brasileiro de Geografia e Estatísticas. Este censo revelou que em todos os estados da federação, inclusive no Distrito Federal, há populações indígenas. Apesar das políticas públicas, esses povos vêm enfrentando problemas reais, como 
invasões e degradações territoriais e ambientais, exploração sexual, aliciamento e uso de drogas, exploração de trabalho, inclusive infantil. Mendicância, êxodo desordenado, causando grande concentração de indígenas nas cidades em condições de miséria, como consequência disso, várias mães estão sendo privadas do convívio com seus bebês. Desse modo, é urgente que se possa buscar novas respostas para garantir a sobrevivência física e cultural desses povos, assegurando as futuras gerações, melhor qualidade de vida.

Ainda segundo o Censo do IBGE, esses 817.963 indígenas são formados por 305 diferentes etnias. No que se refere às línguas faladas, elas são 274; o Censo também demonstrou que cerca de $17,5 \%$ da população indígena não fala a língua portuguesa. Desde 1500 até a década de 1970, a população indígena brasileira decresceu acentuadamente, e muitos povos foram extintos. O desaparecimento dos povos indígenas passou a ser visto como uma contingência histórica, algo a ser lamentado, mas pouco combatido.

A Amazônia no imaginário dos invasores europeus sempre foi pensada como uma região na qual a maioria dos seres mitológicos, provavelmente poderiam ser facilmente encontrados. Ugarte (2003, p.04) enfatiza que as narrativas (escritas e orais) contadas pelos viajantes reforçavam o imaginário permeado por mitos e cenários compatíveis com os que hoje são encenados na arena do bumbódromo 9 .

O próprio nome do maior estado da região Norte parte de um imaginário mitológico. O "Rio das Amazonas", como ficou conhecido já no século XVI o maior dos rios da imensa bacia hidrográfica da região, teve seu nome em prol da lenda das Icamiabas ${ }^{10}$, as Amazonas ${ }^{11}$, depois que relatos mencionaram a existência de mulheres muito semelhantes a elas nas margens do rio. E assim começou a ser configurado um imaginário em torno da região amazônica cujos resquícios detectam-se ainda nos dias atuais.

Conforme mencionado anteriormente, a festa alcançou considerável complexidade, fruto de intensa produção textual, resultando em letras de toadas que levam o espectador a uma mistura de poema com batuque. Alegorias recriam as lendas amazônicas e rituais indígenas, resultantes de um paciente trabalho de pesquisa, com referência no imaginário indígena. Segundo Braga (2002, p. 22), “a consulta a fontes escritas e visuais tem adquirido

\footnotetext{
${ }^{9}$ Arena aonde os Bois Garantido e Caprichoso se apresentam no último final de semana do mês de junho.

${ }^{10}$ Mulheres guerreiras. Espanhóis que exploraram a região, em 1542, juram tê-las encontrado, pessoalmente, onde o Rio Nhamundá desemboca no Amazonas, perto da atual fronteira entre os Estados do Amazonas e do Pará.

${ }^{11}$ As Amazonas na mitologia grega, eram as integrantes de um antiga nação de mulheres guerreiras.
} 
importância crescente entre artistas, compositores, músicos e membros das comissões de artes dos bumbás".

Com a inserção do indígena no espetáculo do Festival de Parintins, este passou a ter mais visibilidade na região, além das aldeias e dos tratados antropológicos que circulam nas universidades. Para Nogueira (2014, p. 162) os bois-bumbás representam os modos de vida das populações indígenas dentro de um contexto artístico capaz de suscitar uma reflexão crítica e agir como veículo de comunicação e conscientização de aspectos culturais, manifestos e latentes, desses povos que viveram e vivem historicamente suas contradições. Por isso, o boi-bumbá representa uma possibilidade de sobrevivência das tradições de cada uma dessas culturas no mundo globalizado.

\subsection{História e preservação cultural}

Patrimônio, em sentido amplo, trata da preservação de uma história, um caminho percorrido pela sociedade, desde seus tempos mais remotos até aos dias de hoje, a construção de uma memória social. Para Funari apud Pelegrini (2006, s/p) a noção de patrimônio tem origem etimológica em "herança paterna", enquanto Ghirardello e Spisso (2008, p. 13) nos ensinam que "Patrimônio é o conjunto de bens, de natureza material e/ou imaterial, que guarda em si referências à identidade, à ação e à memória dos diferentes grupos sociais". Desta forma, bens materiais ou imateriais, pelo seu valor próprio, devem ser considerados de interesse relevante para a permanência e a identidade da cultura de um povo. Assim, é de suma importância o estudo do patrimônio como um caminho para o passado que se interrelaciona com o presente, carregado de sentidos simbólicos.

Compartilhar experiências é reviver o passado, é o que mantém a memória "VIVA". Segundo Le Goff apud Pelegrini (2006, s/p) a "identidade cultural de um país, estado, cidade ou comunidade se faz com a memória individual e coletiva"; a partir do momento em que a sociedade se dispõe a "preservar e divulgar os seus bens culturais", dá-se início ao processo denominado pelo autor como a "construção do ethos cultural e de sua cidadania". Segundo Kraisch apud Rocha (2012, s/p), para discutir a relação entre patrimônio e arqueologia relacionando à preservação deste patrimônio em particular demonstra a necessidade que existe hoje na afirmação dos marcos referenciais e, por que não, identitários, de uma determinada sociedade. Para tanto, deve-se considerar as relações que memória e identidade estabelecem, de um ponto de vista representacional, de base semiótica, através da mediação da cultura material, que é o objeto de estudo da arqueologia. 


\subsubsection{A entrada do elemento indígena no espetáculo}

Partindo do olhar do semioticista da Cultura pela Universidade de Tártu, Yuri Lótman apud Zogaib (1990, p.77), a representação simbólica é importante para preservar a memória porque os símbolos são arcaicos e remetem elementos armazenados na memória, fundamentais para a estrutura da cultura. Para este estudioso:

A symbol always has something archaic about it. Every culture needs a body of texts which serves the function of archaism. Symbols cluster here thickly and with reason because the core group of symbols are indeed archaic and go back to pre-literate times when certain signs (which are as a rule elementary space-indicators) were the condensed mnemonic programmes for the texts and stories preserved in the community's oral memory. Symbols have preserved this ability to store up extremely long and important texts in condensed from. (Lótman, 1990, p.103) ${ }^{12}$

Segundo Assayag (1997, p. 63) foram os referenciais indígenas que promoveram a mudança do bumba-meu-boi em boi-bumbá na região amazônica. O boi-bumbá amazônico enaltece a figura do índio, valorizando sua cultura, seus saberes, sua história milenar. Andrade (2002, s/p) nos ensina que embora de uma maneira estilizada, o boi-bumbá amazônico mostra o indígena, canta o índio, e faz com que todo mundo se volte um pouco para estudar essa cultura. Com toda sua magnitude, a festa fez com surgisse um novo olhar sobre o índio da Amazônia e sua cultura, construindo e reconstruindo histórias.

O boi-bumbá de Parintins nasce a partir do Auto do boi, que nos conta a história de Mãe Catirina, grávida, esposa de Pai Francisco, trabalhador da fazenda, pede ao marido que mate o boi de estimação do patrão para satisfazer seu desejo de comer a língua do boi querido do patrão. O patrão, o amo do boi, descobre e começa-se uma saga para ressuscitar o boi preferido do patrão, brinquedo de estimação da sua filha, a sinhazinha da fazenda. Chamam o Padre, Dr. da Vida ${ }^{13}$ e um pajé. O pajé faz uma pajelança e boi levanta e todos comemoram. Porém, conforme Carvalho (2014, p. 205) alguns participantes começaram a achar que o Auto do Boi tomava muito tempo da apresentação e quebrava a harmonia. Em entrevista (ibidem, p.206) Fred Góes, membro da comissão de arte do Boi Garantido disse:

\footnotetext{
12 Tradução: "Um símbolo tem sempre algo arcaico sobre ele. Cada cultura tem um corpo de textos que serve a função de arcaísmo. Símbolos aglomerados aqui densamente e com razão, porque o núcleo de símbolos é, de fato, arcaico e voltar a pré-alfabetizados vezes quando determinados sinais (que são, em regra elementar espaço-indicadores), formam o condensado mnemônico, programas de textos e histórias conservadas na comunidade da memória oral. Os símbolos têm preservado essa capacidade de armazenar mesmo por períodos extremamente longos e importante em textos de condensado".

${ }^{13}$ Um espécie de boticário.
} 


\begin{abstract}
O boi ressuscita, ali mesmo. (...) no compacto, a gente não faz a morte do boi, porque é o seguinte: a festa, ela é muito para cima, e a morte ela é muito densa, como toda a morte, (risos) é um momento denso, então a gente já tentou colocar, mas aí (...) há uma reação muito grande... "mêrmão tu 'vai' matar o público tu 'leva' pra uma coisa muito densa.
\end{abstract}

Surgia assim, a celebração folclórica, ato que reúne todos os personagens do autodo-boi (Pai Francisco, Catirina, Gazumbá, Padre, Pajé, Amo do Boi, o próprio boi, etc.). Assim, essas figuras passaram a ser meras reminiscências, aludindo ao que um dia figurou no âmago do folguedo. Porém, em 2015, Mencius Melo, então membro da comissão de artes do Boi Garantido, deu um toque de protagonismo a esses personagens dando inclusive "voz" ao Pai Francisco, interpretado por João Paulo Faria, cantando o Auto do Boi dentro da Celebração Folclórica. Devido à ótima repercussão e ao fato de contribuir para as notas da personagem Sinhazinha da Fazenda, tendo em vista a carga dramática da encenação, o Boi Caprichoso acabou adotando também o novo (antigo?) formato.

Assim, o espetáculo do Festival de Parintins ficou dividido em 05 atos: Celebração Folclórica; Figura Típica Regional; Momento Tribal; Lenda Amazônica e Ritual Indígena, compondo um total de 21 itens para julgamento, tendo como pano de fundo uma temática definida de antemão pelo conselho ${ }^{14}$ e comissão ${ }^{15}$ de arte dos bumbás. Assim, trabalha-se na construção do discurso dos bumbás, os mitos selecionados são apropriados pela temática dos bumbás. Para Carvalho, na narrativa central, esses mitos são recontextualizados, na medida em que o discurso do evento consigna à festa popular o papel de uma manifestação herdeira direta e veiculadora de uma suposta essência ancestral, mítica.

Para Carvalho (2014, p.273), é possível afirmar que a construção das bases que sustentam o espetáculo coincide com um discurso esteticamente formulado de maneira a evocar uma consciência temporal baseada em fragmentos de momentos indeterminados de um imaginado passado ancestral, propondo-se a reconstruir significados de lendas e mitos seletivamente recuperados. A estrutura envolve, principalmente, aspectos épicos. Por exemplo, a vitória do herói, o Pajé da tribo, o qual, na cena do Ritual, derrota uma força identificada com o "mal”, salvando o seu povo. Esta força maligna é sempre personificada por uma figura lendária, selecionada da mitologia amazônica. Outras vezes, englobar narrativas

\footnotetext{
${ }^{14}$ A rivalidade no festival é tão grande que os bois adotaram nomes diferentes para suas equipes de trabalho.

${ }^{15}$ Idem
} 
que pretendem retratar um cotidiano - do qual apenas restam elementos residuais na memória coletiva, cotidiano esse a ser ressignificado e reconstruído. E em outras, retratar lutas contra o branco invasor, destruidor.

A representação do signo índio no festival se vale de inúmeras fontes nas quais a toada se destaca como um dos instrumentos mais difusores de pensamentos e ideologias, que reafirmam conceitos que passam a dominar o imaginário popular reproduzido em festas regionais do norte amazônico, onde os artistas dos bumbás apresentam seus trabalhos, sejam alegóricos ou figurinos. Segundo Nakanome (2016, p.73), esse "novo índio", construído no imaginário do artista parintinense, que transforma o "índio folclórico", lúdico de plumas coloridas, no "índio espetacular", de efeitos high tech, inclusive, um possível promotor de uma nova consciência política e identitária. Como escreve Nogueira (2014),

\begin{abstract}
Os artistas colhem narrativas da vivencia cotidiana dos citadinos, dos caboclos e indígenas, principalmente em fontes primarias e secundárias, entre elas contadores de histórias, livros, e documentos religiosos e, assim realizam a interpretação artística da produção intelectual dos povos amazônicos é essa mistura de visões de mundo e experiências da vida nos rios e nas florestas que se manifesta na festa dos boisbumbás de Parintins e nas demais festas que estão sob a sua influência, entre elas a Ciranda de Manacapuru, os Cordões de Peixes de Barcelos, a Dança das Onças de Tabatinga, no Amazonas; e o Festribal de Juruti e os Botos-Vermelho e Tucuxi, de Alter do Chão no Pará. (NOGUEIRA, 2014, p. 171).
\end{abstract}

É a partir deste ponto de vista e através de uma diversificada teia de referências que se alinham as informações sobre o indígena, cultura brasileira, tecendo no imaginário da nação uma visão em torno do signo "Índio" pluralizada e abarrotada de leituras, lugar próprio da arte, base da formação cultural e educacional no Brasil.

\title{
2.5.2. Construindo o espetáculo a partir da narrativa indígena
}

A construção do signo "índio" é consciente de que se trata de um olhar sobre o indígena e não a representação fidedigna deste. Conforme nos informa Silva (2007, p. 157) trata-se de um índio estilizado, para melhor concepção do personagem e formatação do espetáculo. O índio real não serve. É preciso, então, construir, imaginar, criar esse índio almejado. Durante os três dias de festival e mais de 15 horas de apresentações, o espectador mergulha no interior da cultura indígena e cabocla, e conhece melhor a história, a ancestralidade e suas tradições. Mesmo que de forma estilizada, é um resgate de uma história que lhes foi negada ou deturpada.

Para Nakanome, (2017, p.73) são diversas referências para a construção do olhar de determinada coisa, objeto ou indivíduo. Para o estudioso, artesãos e artistas construíram a 
personagem "índio" dentro da festa do boi bumbá a partir de um diversificado referencial que ultrapassa os fundamentos da cultura brasileira, a educação tanto sistemática quanto vivência e a mídia e seu imenso universo de informações "verdadeiras" ou espetaculares. Nos dias atuais, o boi-bumbá de Parintins elegeu o elemento ameríndio presente na cultura popular regional, como o herói trágico do romantismo literário brasileiro - o "dono do país" antes da invasão portuguesa.

O imaginário dos povos da Amazônia constitui um rico arcabouço para os espetáculos folclóricos dos bois de Parintins, personagens e elementos imaginários como fontes de ligação e origem através do mito que nada mais é do que a encenação poética da linguagem. Neste sentido, Lotman (1996 apud MACHADO, 2003, p. 30), afirma que a herança de tradições remotas funcionou como um programa de ação, de intervenção e de experimentação. E que, assim, a tradição seria continuamente recriada, traduzida, fazendo com que o novo sistema se tornasse tributário de outros, que não foram, assim, destruídos, mas recodificados.

\subsection{Linguagens (artes visuais, teatro, música e dança)}

\subsubsection{Os itens Ritual Indígena e Lenda Amazônica}

Nesse contexto, dois itens ganham força dentro do espetáculo: Lenda Amazônica e Ritual Indígena. Não apenas pelas belíssimas e gigantes alegorias, como também pela história a ser encenada. Neste ato, se evidenciam elementos potencializadores do espetáculo como efeitos de aparição, pirotecnia, guindaste e sonoplastia. As lendas surgem das miscigenações das crenças de um povo. No caso peculiar da Amazônia, muitos mitos indígenas foram se transformando em lendas ao longo dos anos, ou seja, as relações entre mitologia indígena e a lenda cabocla são muito próximas.

Na festa de boi bumbá, de acordo com Batalha (2010, p. 100), são muitas as etnias indígenas referenciadas, entre elas estão: Tucano, Carajá, Tupí-Guarani, Kamayurá, SaterêMaué, Munduruku,Tupinambá, Kaxinauá, Apinayé, Mehinakus, Yanomami, Xavante, Makú, Tarian, Wari, Zuruahá, Tapajós, Baniwa, Marubo, Ashsninka, Deni, Katukina, Kulina, Mukaya, Ikolen, Mayoruna, Matis, Waimiri-Atroari, Apurinã, Issé, Ingaricó, Hixkariana, Taulinpang, Juruena, Caiapó, Tikuna, Macuxi, Teneterara, Jarauara, Javaé, Bororo, Matsé, Nambikuara, Parintintin. A utilização dessas diversas etnias indígenas não está apenas na temática de cada bumbá, mas em suas toadas e, consequentemente, no uso de cores, danças, 
vestimentas, plumárias e pinturas corporais, que têm um propósito de trazer um plano visual e estético para as apresentações.

\subsubsection{Lenda Amazônica}

As lendas surgem das miscigenações das crenças de um povo. No caso peculiar da Amazônia, muitos mitos indígenas foram se transformando em lendas ao longo dos anos, ou seja, as relações entre mitologia indígena e a lenda cabocla são muito próximas. Machado (2003) informa que traduzir certo setor em uma das línguas da cultura, transformando-a em uma informação codificada, ou seja, em texto, é o que introduz a informação em memória coletiva. O item Lenda Amazônica, dentro do regulamento do Festival de Parintins, é o item de $\mathrm{n}^{\circ} 15$, definido como o momento em que se revela o mundo mítico, a cultura mística da Amazônia, um mundo de seres encantados, entes da floresta, ora protetores, ora guardiões e heróis do imaginário indígena-caboclo. São eles que protegem a floresta e fazem dela um lugar mágico e onírico. A imaginação que ilustra a ficção da cultura dos povos da Amazônia em sua cenografia e encenação faz com que o acabamento, originalidade e desenvolvimento sejam quesitos de julgamento do item.

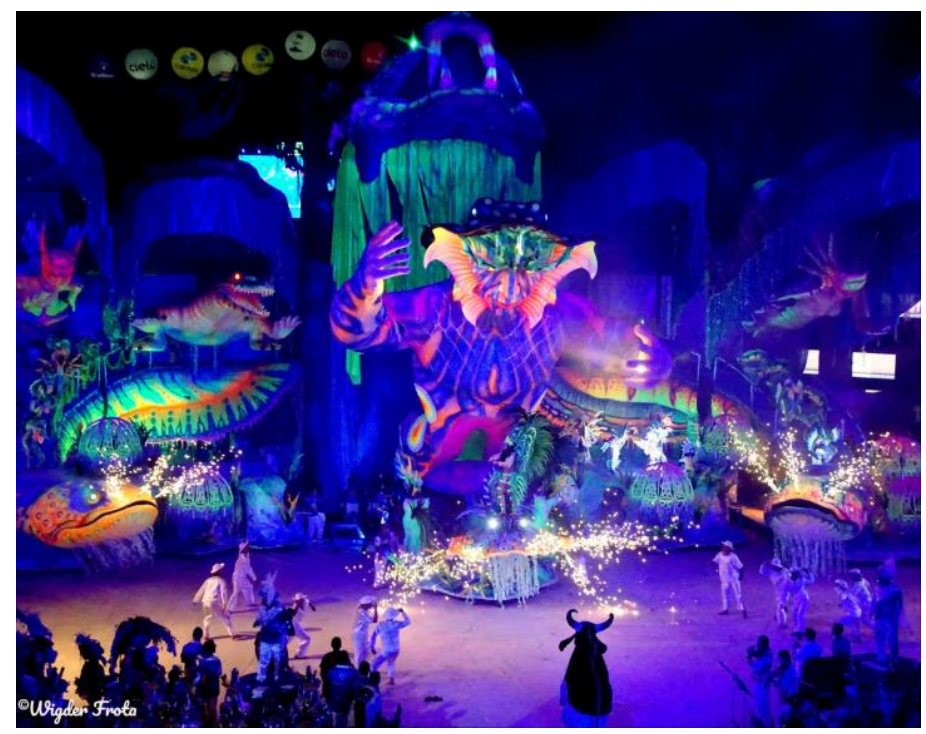

Figura 4 - Lenda Amazônica O Boto Romanceiro - Boi Caprichoso, 2018.

Fonte: fotografia de Wigder Frota.

É na apoteose do item Lenda Amazônica que a índia mais bela da tribo faz sua performance. Ela é a cunhã poranga (Figura 1), mulher bonita em língua Tupi. 


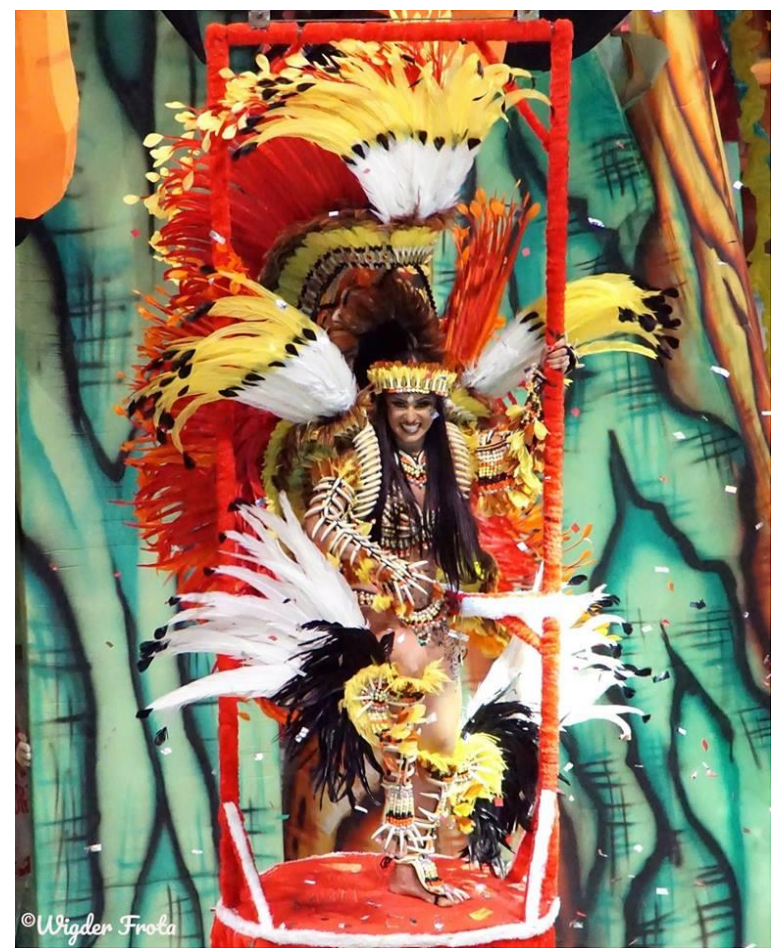

Figura 5 - Isabelle Nogueira - Cunhã Poranga do Boi Garantido

Fonte: fotografia de Wigder Frota.

O item 15 - Lenda amazônica explica acontecimentos misteriosos ou sobrenaturais, misturando realidade e fantasioso, que vão se modificando através do imaginário popular, através da oralidade pelo caboclo ou, pelo índio da região. Exaltando o imaginário amazônico, desconhecido para muitos, com tanta grandiosidade e imbuída de harmonia, que chega a nos transportar para o universo místico e fantástico que se descortina-se a nossa frente.

\subsubsection{Ritual Indígena}

Da antropofagia do povo Tupinambá, conforme relatos de Hans Staden, aos mistérios dos índios morcegos Kuep-Dyep da serra do Roncador; da guerra dos Tariana no rio Uapés ao Couro dos Espíritos. Assim, os bois de Parintins encenam e recriam rituais indígenas para desvendar cenicamente o rico universo e cosmologia desses povos indígenas, dentro de um campo apoteótico, em três atos na arena do Bumbódromo. Os artistas plásticos se debruçam junto com o Conselho ou Comissão de $\operatorname{Artes}^{16}$ para entender as pesquisas antropológicas a fim de recriar os rituais através de imensas estruturas alegóricas e retratar diversos ambientes

\footnotetext{
${ }^{16}$ A rivalidade dentro do festival é tão grande que os bois optaram por nomes diferentes para suas equipes de criação. O Boi Caprichoso tem seu Conselho de Arte e o Boi Garantido, Comissão de Artes.
} 
das crenças dos povos indígenas do Brasil. O espetáculo ganha o suporte essencial através de toadas específicas para esses dois grandes momentos.

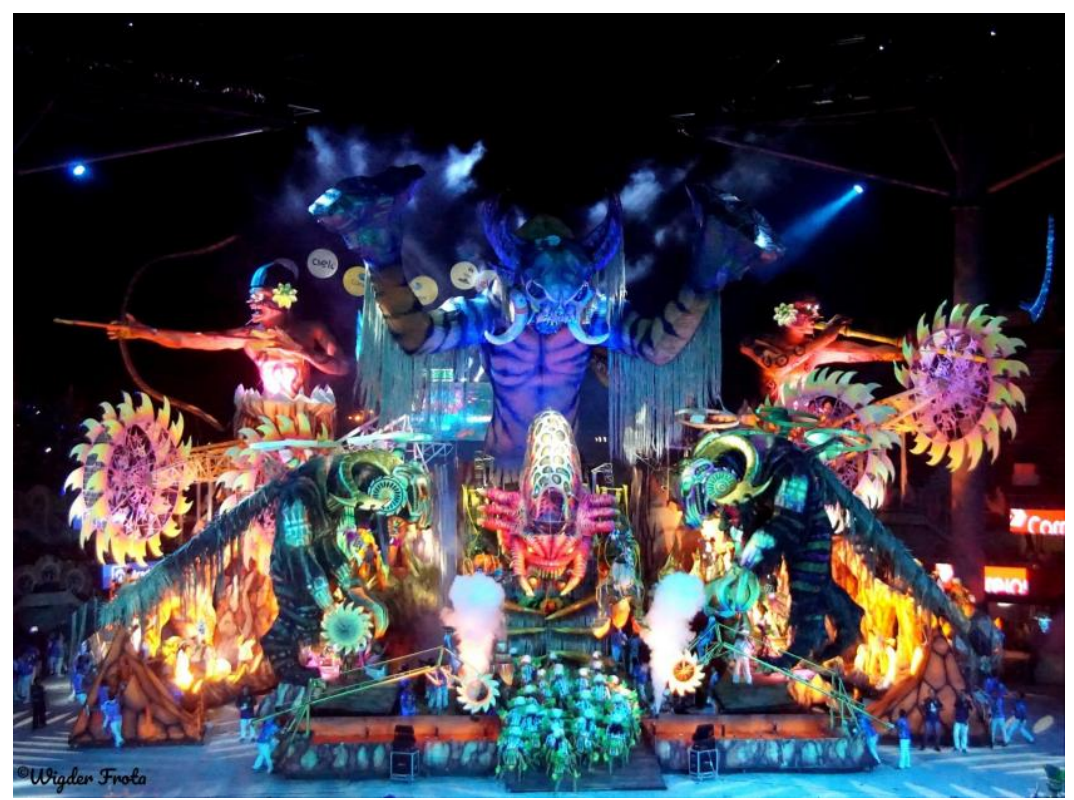

Figura 6 - Ritual Indígena Transcendência Yanomami, Boi Caprichoso 2018.

Fonte: fotografia de Wigder Frota

O Ritual Indígena, um dos momentos mais esperados da noite, é a culminância apoteótica, geralmente o ato final da festa, mas não necessariamente o último, podendo raramente ser representado no início das apresentações. Carregando diversos signos do universo mítico indígena, este item retrata não somente o simbolismo fantástico da mitologia desses povos, mas abrange de forma complexa e ampla, seus conhecimentos e sua maneira de se perceber no mundo, sua fé, e suas relações sociais nas mais variadas dimensões.

A apoteose do Ritual traz o grande xamã, o curandeiro, o pajé. (Figura 07). Ele que conduz a cerimônia indígena em forma de alegoria artística e dramatização. Fidelidade à toada, cantada na cerimônia, desenvolvimento, beleza e encenação são os elementos comparativos em julgamento deste item. 


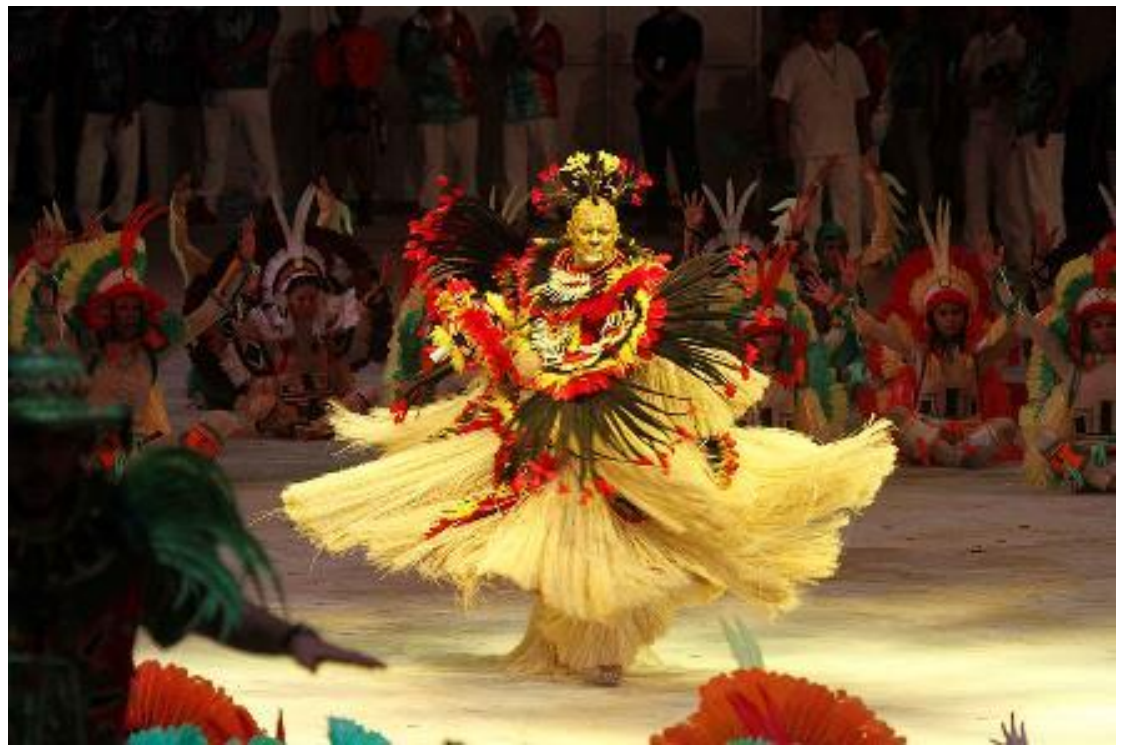

Figura 7: André Nascimento - Pajé do Boi Garantido

Fonte: https://www.visiteobrasil.com.br/noticia/lendas-e-rituais-indigenas-dao-o-tom-no-belo-festival-folcloricode-parintins

Durante o Ritual, podemos entender e sentir alguns mistérios da selva, como: seres fantasmagóricos, danças, tribos, lutas, mortes, animais, a natureza, o Pajé e algumas vezes, a chegada da mulher mais bela da tribo: A Cunhã Poranga.

\section{Considerações Finais}

Concluímos que essa paixão em azul e vermelho é vivida intensamente pelos admiradores e torcedores do Festival de Parintins que é de suma importância para sobrevivência do povo parintinense. Além do festival também ressaltar a diversidade da região amazônica, seu valor como manifestação cultural, inclusive tendo sido reconhecido como patrimônio cultural do Brasil pelo IPHAN - Instituto do Patrimônio Histórico e Artístico Nacional em 2018, também é testemunha do modo de vida, dos afazeres, dos costumes dos caboclos e dos povos indígenas, tornando esta pesquisa, um documento de valor histórico e artístico.

O Festival de Parintins hoje é muito mais do que um mero espetáculo, mas como também um modo de fazer, uma técnica, um bem cultural de natureza imaterial não apenas para a população brasileira, mas quiçá o mundo. Pois tem demonstrado, sua importância ao ressaltar as culturas indígena, afro e cabocla, a miscigenação, a religiosidade, valorizando narrativas simbólicas dos povos que constituem a identidade do povo amazônico. Uma cultura que cria e recria, inventa e se reinventa, mantendo essa tradição do boi-bumbá de Parintins 
que vai passando de geração a geração e que já perdura há mais de 50 anos. Tudo isso, sustentado pelos Bois Garantido e Caprichoso, representados simbolicamente pelas cores vermelho e azul, respectivamente. Percebemos, assim, o porquê dessa festa ser plena dos mais variados significados. Desta forma, imaginários, histórias e as memórias dos povos aqui mencionados, encontram no festival, significância e se contextualizam num elo simbólico que envolve tradição e modernidade.

Esta pesquisa buscou também compartilhar parte do processo criativo, percebido, vivenciado e elaborado como espetáculo e somar-se ao esforço de tantos estudiosos do tema e criar um arcabouço epistemológico dentro do Festival de Parintins, o que certamente servirá futuramente para dar sustentação e contribuir com esta área de conhecimento que ainda carece de legitimação. Sem dúvida, o debate precisa continuar.

\section{Referências}

ARGAN, Giulio Carlo. Guida ala storia dell'arte. Tradução de M.F.Gonçalves de Azevedo. Lisboa. Editorial Estampa, 1992. 2a edição.

AMÉRICO, Ekaterina Volkova. Alguns aspectos da semiótica da cultura de Iuri Lótman. 2012. Tese (Doutorado em Literatura e Cultura Russa) - Faculdade de Filosofia, Letras e Ciências Humanas, Universidade de São Paulo, São Paulo, 2012. Disponível em http://www.teses.usp.br/teses/disponiveis/8/8155/tde-07112012-124602/pt-br.php. Acesso em: 2018-12-21.

BRAGA, Sérgio Ivan Gil. Os bumbás de Parintins. Rio de Janeiro: Funarte/ Editora Universidade do Amazonas, 2002.

Editora da Universidade Federal do Amazonas, 2007.

ELIADE, Mircea. Mito e realidade. Tradução Pola Civelli. São Paulo: Perspectiva, 2016.

LOUREIRO, João de Jesus Paes. Cultura Amazônica: Uma Poética do Imaginário. $5^{\mathrm{a}}$ edição. Manaus. Editora Valer. 2015.

LOTMAN, Yuri. La semiosfera I. Traduzido por Desiderio Navarro - Ediciones Catedra (Grupo Allay.), S. A.), 1996. Juan Ignacio Luca de Tena, Madrid.

La semiosfera III. Traduzido por Desiderio Navarro - Ediciones Catedra (Grupo Allay.), S. A.), 2000. Juan Ignacio Luca de Tena, Madrid.

MACHADO, Irene. Escola de Semiótica, São Paulo: Ateliê Editorial, 2003.

MESQUITA, Valter. Semioses na web: os processos comunicativos do google art Project. $1^{\mathrm{a}}$ edição. Curitiba. Appris. 2016. 
PELEGRINI, Sandra C. A. Cultura e natureza: os desafios das práticas preservacionistas na esfera do patrimônio cultural e ambiental. Rev. Bras. Hist., São Paulo, v. 26, n. 51, p. 115140, Junho de 2006. Disponível em:

http://www.scielo.br/scielo.php?script=sci_arttext\&pid=S0102-01882006000100007. Acesso em 22.12.2018.

Revista Boi Caprichoso 2013. O centenário de uma paixão. Caprichoso, Parintins, 2013.

Revista Boi Garantido 2013. O Boi do Centenário. Parintins, 2013.

SANCHES, Cleber. Fundamentos da cultura brasileira. Manaus: Valer, 2009.

SILVA, Aracy Lopes da. Mitos e cosmologias. Disponível em: <https://pib.socioambiental.org/pt/c/no-brasil-atual/modos-de-vida/mitos-e-cosmologia〉.

Acesso em 06.12.2018 as 23:03.

TENÓRIO, Basílio. A cultura do boi bumbá. Parintins-AM: Editora e gráfica João XXIII, 2016.

VALENTIN, Andreas. Caprichoso, a terra é azul = The Amazon Music a da dance festival. Andreas Valentin, Paulo José Cunha. Rio de Janeiro. 1999

ZAMBONI, Silvio. A pesquisa em arte. $3^{\text {a }}$ edição. Campinas, SP. Autores associados. 2006. Coleções polêmicas do nosso tempo, 59. 